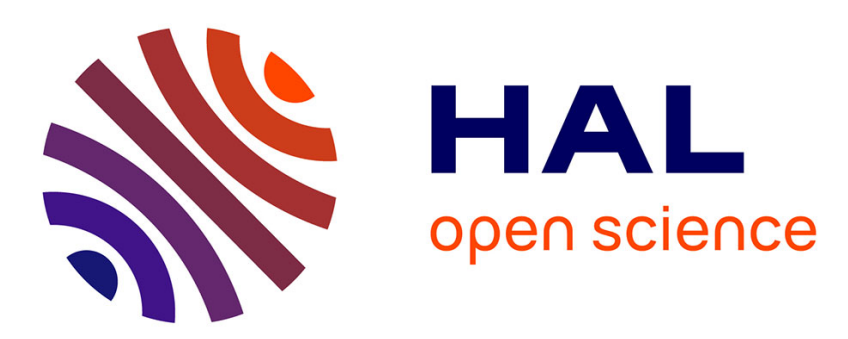

\title{
Conceptual and critical development in student teachers: first steps towards an integrated comprehension of osmosis
}

\author{
Laurence Viennot, Nicolas Décamp
}

\section{- To cite this version:}

Laurence Viennot, Nicolas Décamp. Conceptual and critical development in student teachers: first steps towards an integrated comprehension of osmosis. International Journal of Science Education, 2016, 38 (14), pp.2197 - 2219. 10.1080/09500693.2016.1230793 . hal-01738709

\section{HAL Id: hal-01738709 \\ https://hal.science/hal-01738709}

Submitted on 20 Mar 2018

HAL is a multi-disciplinary open access archive for the deposit and dissemination of scientific research documents, whether they are published or not. The documents may come from teaching and research institutions in France or abroad, or from public or private research centers.
L'archive ouverte pluridisciplinaire $\mathbf{H A L}$, est destinée au dépôt et à la diffusion de documents scientifiques de niveau recherche, publiés ou non, émanant des établissements d'enseignement et de recherche français ou étrangers, des laboratoires publics ou privés. 


\title{
Conceptual and critical development in student teachers: First steps towards an integrated comprehension of osmosis
}

\author{
Laurence Viennot and Nicolas Décamp \\ LDAR, Laboratoire de Didactique André Revuz, EA 4434 \\ http://dx.doi.org/10.1080/09500693.2016.1230793
}

\begin{abstract}
In a context of strong valuation of competences in physics teaching, students' critical thinking is widely advocated but there is also a risk that conceptual structuring be disregarded. For that reason, this investigation is focused on possible links between the development of critical attitude and conceptual understanding. We analyzed in detail how conceptual comprehension and critical attitude develop when a person confronts various explanations of a nonobvious topic. To this end, we conducted a fine grained analysis of five prospective teachers' critical and conceptual development during a one hour and a half interaction with an expert. This investigation completes a series of three previous studies addressing the same general research question in respect of three different physics topics. In this instance, the focus is on the topic of osmosis. A content analysis led us to identify some lines of reasoning that we expected to observe as well as conceptual targets for the interviews. In line with an integrative perspective, these conceptual goals provide some opportunities to link osmosis phenomena with a molecular approach. The transcripts were processed following two lines of analysis, one conceptual and the other focusing on critical attitude as well as metacognitive and affective affects. The findings confirm the significant occurrence of the expected lines of reasoning. They also suggest that students need to reach a threshold of comprehension, beyond logical necessity, before expressing critiques toward inaccurate texts or their previous views ("delayed critique"). Students' questions about the meanings of current phrases relating to pressure in liquids are shown to play a decisive role to activate their potential of critique as well as significant conceptual steps forward. In discussing our results, we explain how this study contributes to a holistic picture of student teachers' conceptual and critical co-development when interacting with an expert. The prevalence of "delayed critiques" aligns with our previous results. Additionally, a more specific finding of this study is the precise localization of events that are likely to trigger rapid conceptual and critical evolution. A discussion about further research and perspectives concerning the teaching of osmosis and students' formation to critique ends the paper.
\end{abstract}

\section{Introduction}

One important aspect of physics teaching is to promote conceptual understanding through coherent explanations of physical phenomena. In recent years, however, science teaching objectives for secondary education have placed stronger emphasis on skills than on concepts; according to the European Commission (2015), 'science education should focus on competencies'. From this perspective, the development of critical faculties becomes a key objective, and there is a risk that conceptual structuring may be 
disregarded. In that context, a question arises: can students really evolve critically without some conceptual foundation? Our main research question then asks: What links can be identified between the development of conceptual understanding and critical attitude in physics students?

More precisely, we considered it fruitful to analyze in detail how conceptual comprehension and critical attitude develop when students are confronted by various explanations of a nonobvious topic. We chose to conduct a series of investigations of this type, each devoted to a particular physics topic. Indeed, the research question as articulated requires both an analysis of student teachers' critical attitude and an in-depth investigation of their conceptual understanding in the different steps of interaction with an expert. This has two consequences. First, such in-depth studies mean long interviews with a (then) limited number of people. Second, the topic in question is itself a relevant variable. Given this double constraint, it seems likely that any convergence in results across different topics would lend stronger support to our conclusions than a single investigation - all the more so in light of the small sample. Similarly, any divergence between results across different topics would pose useful questions about the contextual dependence, validity, or complementarity of our results. Based on a preliminary study (Mathé \& Author 1 2009), two more focused studies were therefore conducted, related to radio carbon dating (Author 2 and Author 1 2015) and the working principle of a survival blanket (Author 1 and Author 2 2016). In the present paper, we compare our results concerning osmosis with those from the previous investigations. Rather than being the prior target of the study, each of the chosen topics serves to address our main research question. However, this by no means exempts us from sound content analysis of each topic or from precise definition of what would constitute conceptual progress in this regard. That being so, each study supplies information that may usefully inform future research investigating comprehension of the topic in question, and we will discuss the extent to which this can be said of the present investigation.

As the development of critical faculties is of particular importance in the formation of student teachers, we thought it useful to document the intellectual processes that may help or hinder this development at this level. The study is based on interviews with five student teachers in their last year of formation at university.

Osmosis is a complex topic that seemed likely to place the participating student teachers in a situation of uncertainty, which was a priori a favourable factor for present purposes. Additionally, as already signalled by several authors (e.g. Kramer and Myers 2012, Shen et al. 2014), many textbooks or informal documents convey inaccurate ideas about this topic, which may promote critical discussion. Given the wide occurrence and persistence of such ideas, we considered it fruitful to explore how our students might be led to an integrated comprehension of osmosis - that is, to a sense of the links between its macroscopic and microscopic aspects.

In so doing, we propose a double exploration of students' responses to diverse analyses of this complex topic. As well as documenting student teachers' reasoning about osmosis, our study examines the possible interplay between the development of conceptual comprehension and critical thinking in this population. Following an elaboration of our rationale, the present paper reports our content analysis and anticipated lines of reasoning among student teachers. After describing interviews, coding procedure and findings, we discuss how these results compare with our previous results, and how they might inform future research and the design of learning environments. 


\section{Rationale}

This investigation relies on an epistemological position, in which physics is seen as a science that pursues a coherent and parsimonious description of the world, and a few laws account for a large set of phenomena within a specified range of validity (Ogborn, 1997). In such a framework, the minimum requirement in terms of critique is the ability to detect self-contradictory statements, or statements that contradict basic laws of physics, and to recognize incomplete explanations. Here, we envisage situations where contestable statements can be identified on the basis of relatively simple arguments; by 'simple' we mean what may be expected of the population in question.

This formulation omits much of the diversity of 'critical thinking' as defined by cognitive scientists - e.g. 'the correct assessing of statements' (Ennis 1992), or 'the appropriate use of reflective scepticism within the problem area under consideration' (McPeck 1981). Our focus is more restrictive, and excludes several components of critical thinking. Among these is the ability to criticize the sources of texts with respect to possible asymmetries of power (e.g. Habermas 1981) or those listed by JiménezAleixandre and Puig (2012). In short, we posit a 'critical attitude', evidenced by interviewees' critical comments in their search for coherence, comprising critiques of inaccurate documents or statements and/or self-critiques of their own previous responses. The phrase 'critical passivity' designates an absence of such indicators, and an interval during which an interviewee exhibits a critical attitude will be characterised as a 'critical moment'. 'Critical development' refers here to more frequent occurrences of a critical attitude in a given individual. More speculatively, we posit that a critical attitude indicates the activation of a 'critical potential' - that is, given the relatively short duration of an interview (even a 'long' interview), our use of the term 'potential' signifies that a new attitude does not imply an overall change in the interviewee's intellectual resources, and that there was an existing ability to formulate critical comments, even if their expression was delayed.

It is important to note that the adoption of a critical attitude vis à vis an explanation requires some awareness of one's own state of comprehension and some idea of what it is to learn science. These may be characterized as 'metacognitive' features. Echoing Vermunt's (1996) position, we see critical attitude as a component of metacognition - that is, as an essential condition for active self-regulation of one's own learning processes.

Additionally, enacting a critical attitude is a means of expressing dissatisfactionmore positively, it evidences a search for intellectual satisfaction (Author 1 2006, Feller et al. 2009, Mathé and Author 1 2009). That being so, the present inquiry also documents the extent to which the intellectual path proposed to interviewees fosters their 'intellectual satisfaction'. We also take the view that posing questions that directly challenge an explanation implies an active search for meaning, beyond a mere attitude of doubt and depending in part perhaps on psychological factors such as self-esteem or 'self-efficacy' (Bandura 2001). As these metacognitive and affective components of students' critical attitude seem a priori difficult to unravel, they are designated here by the compound label metacognitive-critical-affective (MCA). We examine how these $M C A$ factors may evolve in conjunction with conceptual comprehension. In other words, our aim is to characterize students' 'intellectual dynamics' during interaction with an interviewer.

This decision to investigate a process of co-development demands fine-grained analyses of long interactive sessions with individuals (about 1h 30'). Framing the interaction as a teaching experiment (Komorek and Duit 2004), we used the concept- 
driven interactive pathway format (Author 1 and de Hosson, 2015), orienting the scenario as a tool for conceptual integration. The very idea of inviting students to work on both critical and conceptual planes constitutes, we suggest, an integrative perspective (Linn et al. 2006). Here, however, we use the term 'integrative' in the more specific sense of an attempt to link phenomenological and thermodynamic knowledge to the molecular level. This approach will be justified in the next section.

Finally, it is important to emphasize that the main goal of such a 'teaching experiment' is to address the research question rather than to evaluate a particular teaching sequence. Nevertheless, we would also expect this investigation to provide useful information for future research concerning the evaluation of teaching sequences on osmosis.

\section{Content Analysis and Targeted Conceptual Steps}

As recalled by Kramer and Myers (2012), 'Osmosis is the flow of solvent across a semipermeable membrane from a region of lower to higher solute concentration'. A semipermeable membrane allows solvent molecules (but not solute molecules) to pass. In an analogous situation, gas can be analyzed in the same way. A prototypical situation used to illustrate osmosis (ibid.) is shown in Figure 1.

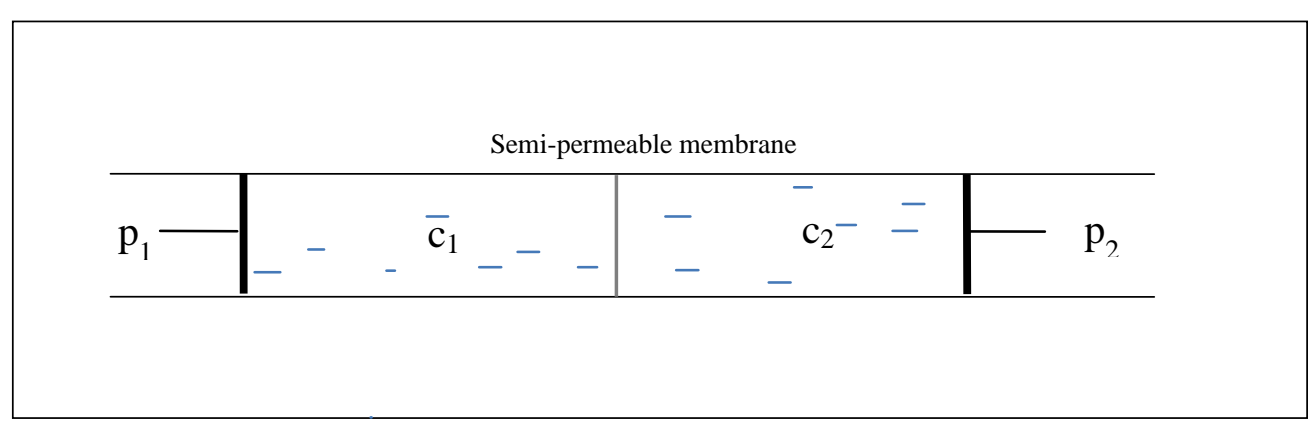

Figure 1. Osmosis between two solutions of concentrations $c_{1}$ and $c_{2}$ and pressures $\mathrm{p}_{1}$ and $\mathrm{p}_{2}$ (horizontal format: Kramer and Myers 2012)

More commonly, an alternative version of this situation employs a U-tube. Its two branches constitute the two 'regions' mentioned above, separated by a semipermeable membrane at the bottom of the tube (Figure 2).

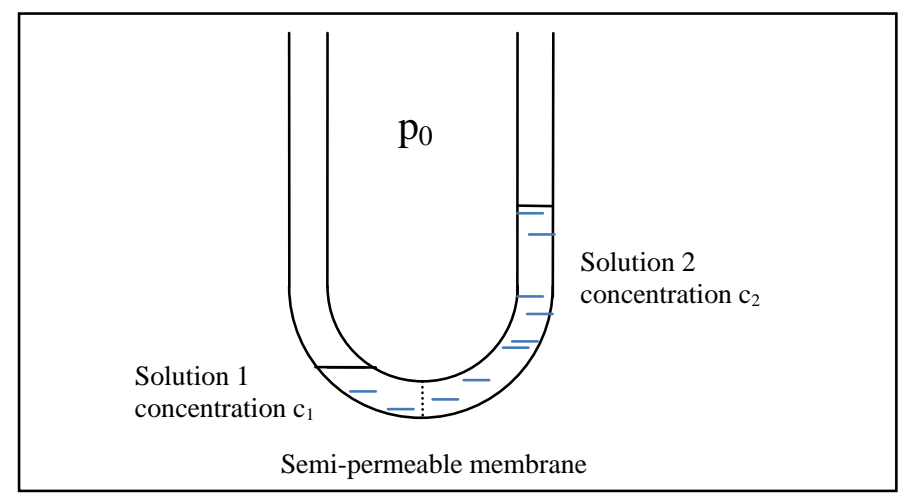


Figure 2. Osmosis between two solutions of concentrations $c_{1}$ and $c_{2}$ in a U-tube under external pressure $\mathrm{p}_{0}$

The difference in pressure between the two compartments at equilibrium is called 'osmotic pressure' $(\pi)$. Beyond this phenomenological description, the conditions of equilibrium and of osmotic transformation can be derived from a comparison between the chemical potentials of the solvent in the two compartments. At equilibrium, these chemical potentials are equal, ensuring that the flows of solvent in both directions are equal. In the simple case of osmosis involving two perfect gases, it is possible to define partial pressures for both components of the mixture (A and B) and to see total pressure as the sum of these partial pressures. Then, equity between chemical potentials of the gas that can cross the membrane (say A) is associated with equal partial pressures and equal concentrations (at given temperature) of this gas across the membrane. In this last case, the value of osmotic pressure $\pi$ is $c_{B} k T\left(c_{B}=\right.$ volume concentration of gas $B ; k=$ Boltzmann constant; $\mathrm{T}=$ absolute temperature), which is the kinetic pressure of the gas that cannot cross the membrane. This expression $\pi=\mathrm{c}_{\mathrm{B}} \mathrm{kT}$ is also valid at first order in $\mathrm{c}_{\mathrm{B}}$ for dilute solutions of small molecules (solute B) (Cabane and Hénon 2003, p. 189).

On this basis, several steps of comprehension of osmosis were identified in framing the interviews.

Interview step 1 operates at the phenomenological level as follows: for given constituents, the two determinants of osmosis are the difference in solute concentration and pressure across the membrane; equilibrium is possible only when these two differences are both either zero or non-zero; in disequilibrium, there is a net flow of solvent from less concentrated (solute) solution to more concentrated (solute) solution; equilibrium occurs when a physical quantity characterizing the solvent is equal on both sides of the membrane.

In defining subsequent interview steps, we took the following issues into account. As noted above, the chemical potential of the solvent is the quantity that must be the same across the membrane at equilibrium, which may result in a counterintuitive situation, such as differing values of solvent concentration at equilibrium (Kramer and Myers 2012, p. 696). This can be understood as a result to be accepted and learned, but the persistence of inappropriate lines of reasoning (see next section) suggests that deeper comprehension (at a molecular level) may prove fruitful. This introduces a new and complex domain of reflection on the effects of intermolecular interactions. Ultimately, comprehension of this aspect involves awareness that, in a solution (or a gaseous mixture) of two constituents A (solvent) and B (solute), pressure is the sum of several terms:

$$
\mathrm{p}=\mathrm{p}_{\text {kinB }}+\mathrm{p}_{\text {kin } \mathrm{A}}+\mathrm{p}_{\text {int all }} \text { with } \mathrm{p}_{\text {int all }}=\mathrm{p}_{\mathrm{AA}}+\mathrm{p}_{\mathrm{AB}}+\mathrm{p}_{\mathrm{BB}},
$$

where $\mathrm{p}_{\mathrm{AA}}, \mathrm{p}_{\mathrm{AB}}$, and $\mathrm{p}_{\mathrm{BB}}$ are the respective (negative) contributions to pressure (often called "pression dynamique" in French) (Diu et al. 1989, p. 356) caused by attractive interactions between solvent molecules (AA), solvent and solute molecules (AB) and solute molecules (BB). This implies that it is impossible to define partial pressures unless interactions between solvent and solute can be neglected with respect to the other terms.

However, accessing this view requires some understanding of the concept of (negative) pressure due to interactions, and some awareness of two other ideas: that if the solvent is a real gas or a liquid, $\mathrm{p}_{\mathrm{AA}}$ is non zero; and that, in the case of a liquid A, $\mathrm{p}_{\mathrm{AA}}$ is of same order of magnitude as the kinetic pressure $\mathrm{p}_{\text {kin A }}$ (Diu et al. 1989, p.361364). These ideas are necessary to understand that, in cases of reduced pressure - for instance, if a glass of water is brought to the top of Mont Blanc at constant 
temperature-molecular interactions adapt to the new situation and the attractive forces increase due to a dilatation of water, so reducing the difference between kinetic and (absolute values of) 'interactive' terms of pressure. Another pivotal idea concerns the gaseous mixture of perfect gases, and the impossibility of seeing pressure in such a mixture as the sum of two partial pressures, each one relating to a single component, when there are noticeable interactions between the two gaseous components.

Interview step 2, then, centred on these aspects, which can be summarized as follows: the existence of attractive molecular interactions in a pure liquid, explaining its adaptation to a change in pressure; and the existence of interactions between solvent and solute molecules (or ions), preventing fruitful reasoning with 'partial pressures'. We suggest that understanding this is a prerequisite in renouncing inaccurate popular ideas about osmosis. These conceptual targets entail a molecular approach, representing progress towards an integrated understanding of the phenomenon. This intellectual step extends beyond phenomenology or even reference to chemical potentials. In particular, it demands an understanding of pressure in liquids at molecular scale, if only in a pure solvent.

Interview step 3 bears on the adaptation of the solvent to a change in solute concentration in the most general case. This presents an opportunity to confront the complexity of the situation when simple analyses of interactions between solvent and solute prove insufficient, and the use of chemical potentials seems the only safe option.

\section{Expected lines of reasoning and existing texts}

The study examined the extent to which the above conceptual elements might give rise to specific lines of reasoning (LRs) in interviewees, focusing on LRs that are likely to hinder comprehension of osmosis. Given the often observed resonance between students' ideas and explanations currently found in textbooks (Author 1 2006), we examined-without statistical pretension-a number of textbooks and Internet documents as possible sources.

Concerning interview step 1 , it is striking that solute concentration is often presented as the only determinant of osmotic equilibrium, so that equilibrium is said to be reached when the two liquids in contact with the membrane are of the same solute concentration.

Osmosis is the passage of solvent molecules, generally water, through a semi-permeable membrane, from the less concentrated medium (hypotonic) to the more concentrated (hypertonic). This stops when the two liquids separated by the membrane have reached the same concentration. <http://www.futura-

sciences.com/magazines/matiere/infos/dico/d/chimie-osmose-5766>

The same idea is explicitly stated in some research papers or textbooks on biology education (e.g. Wang 2015, 249). We suggest that an emphasis on the system's 'tendency' to maximize entropy may favour this too exclusive focus on solute concentration. It may be thought that, if solute concentration is the cause of osmosis, the phenomenon will reach equilibrium (only) when the solute concentrations are equal:

Osmosis is the spontaneous net movement of solvent molecules through a partially
permeable membrane into a region of higher solute concentration, in the direction that
tends to equalize the solute concentrations on the two sides.
<http://en.wikipedia.org/wiki/Osmosis>

For all these reasons, we would expect to find that students' discourse around osmosis focuses exclusively on concentration of solute (line of reasoning labelled LR $\alpha$ ). 
This expectation is supported by results reported by Odom and Barrow (1995, p. 55) and by Shen et al. (2014, p.1788).

Given the above descriptions of osmosis in terms of 'tendency', this fuzzy landscape may hamper students' comprehension of osmotic pressure. For instance, Shen et al. (2014, p.1789) reported students' use of anthropomorphic expressions such as 'Water wants to dilute solute' (see also Zukerman 1993). On that basis, we would expect to find similarly vague accounts of pressure and/or teleology (LR $\delta)$.

In relation to interview step 2, another striking feature of some texts was their account of fluid pressure as the mere sum of 'pressure of the solute' and 'pressure of the solvent' (or 'pressure due to water molecules'), as if there was no interaction between pressure and solvent. Note that this approach leads in a very simple way to the classical expression $\pi=\mathrm{c}_{\mathrm{B}} \mathrm{kT}$ ( $\mathrm{B}$ is the solute):

Pressure inside the cell equals the sum of pressures due, on the one hand, to water molecules and, on the other hand, to $\mathrm{NaCl}$ molecules.

$\mathrm{P}_{\mathrm{i}}=\mathrm{P}_{\mathrm{i}}\left(\mathrm{H}_{2} \mathrm{O}\right)+\mathrm{P}(\mathrm{NaCl})$

Pressure outside the cell is due only to water molecules.

$\mathrm{P}_{\mathrm{e}}=\mathrm{P}_{\mathrm{e}}\left(\mathrm{H}_{2} \mathrm{O}\right)$

Osmotic pressure is the difference between pressures at equilibrium across the semi permeable membrane.

$\pi=\mathrm{P}_{\mathrm{i}}-\mathrm{P}_{\mathrm{e}}=\mathrm{P}_{\mathrm{i}}\left(\mathrm{H}_{2} \mathrm{O}\right)-\mathrm{P}_{\mathrm{e}}\left(\mathrm{H}_{2} \mathrm{O}\right)+\mathrm{P}(\mathrm{NaCl})$

Water flux across the membrane stops when internal and external pressures are the same. Then one gets $\pi=\mathrm{P}(\mathrm{NaCl})(\ldots)$

Where this model is valid, $\mathrm{NaCl}$ molecules, or more generally solute molecules in a diluted solution, behave like perfect gas molecules $(\pi=\mathrm{kcT})$. (Bouissy et al. 1987, 109)

As noted above, a simple additive view of total pressure as a sum of two terms (LR $\sigma$ ), each referring to a given component of the solution, neglects the solvent/solute interactions (LR $\psi)$. As previously suggested by Kramer and Myers (2012), this line of reasoning may be of interest in the present context, and indeed, the responses of students confronted with this type of argument offered some clues to their critical attitude in this regard.

As emphasized above, achieving some critical distance from these simple views requires some understanding of the role of molecular interactions in pressure in fluids. Against this, the prevalent perfect gas model and the focus on collisions tends to promote the exclusive role of 'kinetic pressure' $(\mathrm{LR} \chi)$. In relation to the geometrical adaptation of fluids to change in pressure, secondary school physics courses commonly suggest that water is incompressible. We would argue that this view of an invariable water volume $(\mathrm{LR} \gamma)$ is a potential obstacle to comprehending pressure in a fluid (Besson \& Author 1 2004), as students may believe that nothing can change in liquid water $(\mathrm{LR} \omega)$. A variant $\left(\mathrm{LR} \gamma^{\prime}\right)$ of this idea would be that water volume can change only with temperature.

We draw on in-depth interviews to document the importance of these lines of reasoning ( $\left.\mathrm{LR} \alpha, \mathrm{LR} \delta, \mathrm{LR} \gamma, \mathrm{LR} \gamma^{\prime}, \mathrm{LR} \chi, \mathrm{LR} \omega, \mathrm{LR} \sigma, \mathrm{LR} \psi\right)$ as possible obstacles to comprehending osmosis, along with others that emerge from our experiment. Thus, the idea that water would migrate from high (solute) concentration to low (LRE: see also e.g. Odom and Barrow 1995, p.54) was observed in our students. According to LR $\tau$, pressure should be the same on both sides of the semipermeable membrane at the bottom of a U-tube for two solutions with different solute concentrations. Finally, an elaboration on the inalterability of liquid water was that there are interactions in water but that these are not modified when water pressure changes (LR $\eta$ ). 
Note that some inaccurate ideas reported in the literature were not observed in our sample. AlHarbi et al. (2015, p.239) found that students believed that solvent molecules would 'stop moving' at equilibrium. To the extent that this implies an absence of Brownian motion, this idea was not observed in our interviewees. Neither did we find evidence of the finding reported by Odom and Barrow (1995, p.52) that some students associated osmosis with 'living forces'

Table 1 recapitulates the steps that we propose should be taken to arrive at an integrated comprehension of osmosis, along with lines of reasoning that we would expect to recur in interviewees' arguments. 
It is worth noting that, given the structure of our investigation, conceptual exploration could not be allowed to dominate the discussion. For this reason, our account of students' inaccurate views about osmosis makes no claim to be exhaustive.

Table 1. Some steps on the way to comprehension of osmosis and expected lines of reasoning

\begin{tabular}{|c|c|c|}
\hline & Conceptual content involved & Expected student LRs: possible stumbling blocks \\
\hline \multirow[t]{4}{*}{ Step 1} & $\begin{array}{l}\text { Starting with the same solute concentration and } \\
\text { pressure on both sides of the membrane and adding } \\
\text { some solute on one side, net flux of solvent through } \\
\text { the membrane will be toward the more } \\
\text { concentrated (in solute) solution until a new } \\
\text { equilibrium is reached. }\end{array}$ & $\begin{array}{l}\varepsilon \quad \text { A flux should be observed from the more concentrated } \\
\text { solution toward the less concentrated solution. }\end{array}$ \\
\hline & $\begin{array}{l}\text { At equilibrium, solute concentration is not the same } \\
\text { in the two branches of the U-tube }\end{array}$ & $\begin{array}{l}\alpha \quad \text { Solute concentration is the same on both sides of the } \\
\text { membrane at equilibrium in the U-tube. }\end{array}$ \\
\hline & $\begin{array}{l}\text { There is a difference in pressure }(\pi) \text { on either side } \\
\text { of the membrane at equilibrium. }\end{array}$ & $\begin{array}{l}\tau \quad \text { Pressure should be the same on both sides of the } \\
\text { membrane. 'Compensation' } p_{\text {osmotic }} / p_{\text {hydro }}\end{array}$ \\
\hline & $\begin{array}{l}\text { By definition, } \pi \text { is osmotic pressure. In a book: } \\
\pi=c_{B} k T \text { or else } p_{k i n} B\end{array}$ & $\begin{array}{l}\text { } \delta \text { Osmotic pressure is 'what makes that' —'deus ex } \\
\text { machina', a 'tendency'. }\end{array}$ \\
\hline \multirow[t]{2}{*}{ Step 2} & $\begin{array}{l}\text { Meaning of pressure in a pure fluid: the role of } \\
\text { collisions and attractive interactions }\end{array}$ & $\begin{array}{l}\chi \text { Pressure is only a matter of collisions and it is } \\
\text { therefore equal to kinetic pressure; the role of } \\
\text { molecular interactions is disregarded. }\end{array}$ \\
\hline & $\begin{array}{l}\text { Mechanism of fluids' isothermal adaptation to a } \\
\text { change in pressure }\end{array}$ & $\begin{array}{ll}\omega & \text { Nothing changes in water, water is water. } \\
\gamma & \text { Water (and fluids in general) is (are) incompressible. } \\
\gamma^{\prime} & \text { Water may expand/contract due to temperature } \\
& \text { change only. } \\
\eta & \text { Attractive interactions in water always stay the same. }\end{array}$ \\
\hline
\end{tabular}

When a semipermeable membrane separates a perfect gas A and a mixture of perfect gas A and B, allowing only molecules of $\mathrm{A}$ to pass, then, at equilibrium, concentration of $\mathrm{A}$ and partial pressure of $\mathrm{A}$ are the same in the two compartments.

As $\mathrm{p}=\mathrm{p}_{\text {kin } \mathrm{B}}+\mathrm{p}_{\text {kin } \mathrm{A}}$ holds in the two compartments, $\pi=\mathrm{p}_{\text {kin } B}$

This type of analysis ceases to be valid when there are molecular interactions between components (in which case it is not possible to separate terms of pressure related to each component)

Concerning solutions, the same limitation hinders analysis in terms of partial pressures.

Step 3 In a solution or gaseous mixture, pressure is

$\mathrm{p}=\mathrm{p}_{\text {kin } \mathrm{B}}+\mathrm{p}_{\text {kin } \mathrm{A}}+\mathrm{p}_{\text {int all }}$, where $\mathrm{p}_{\text {int all }}$ refers to

all intermolecular interactions $\mathrm{A} / \mathrm{A}, \mathrm{A} / \mathrm{B}$ and $\mathrm{B} / \mathrm{B}$.

When intermolecular interactions between the two components are not negligible, evaluation of $p_{\text {intall }}$ and analysis of the physical quantity (or quantities) that is (are) the same across the membrane at equilibrium ceases to be easily accessible. The equality of chemical potentials of the solvent constitutes the only valid point of entry to this problem.

A: solvent; B: solute; Col. 2: some conceptual targets for integrated comprehension of osmosis; Col. 3: some lines of reasoning (LRs) suggested by certain textbooks and previous research, or emerging from our interviews, that may constitute obstacles to coherent comprehension of osmosis. All letters in bold constitute codes used below. Grey boxes correspond to themes discussed in the context of a glass of water displaced from sea level to the top of Mont Blanc. 


\section{Method}

\section{The interview as concept-driven interactive pathway (CDIP)}

Drawing on the teaching experiment method (Komorek \& Duit, 2004), we designed the conditions for a 'concept-driven interactive pathway' (CDIP: Author 1 and de Hosson 2015): 'This takes the form of a series of events-input from interviewer, reactions from the student, possibly experiments, questions and requests, discussionsorientated towards conceptual acquisition'. The interaction between interviewer and interviewee is structured and guided, allowing students to expose their initial thoughts and reactions to various events. The CDIP is progressive, in that what is understood at one step may serve to construct the next stage of knowledge. It also offers opportunities for students to critique presented textual or iconic explanations. In such a framework, knowledge that is 'already there' may be reorganized and extended during the interview. Although close to a 'teaching-learning' format, this type of interaction is used as a research tool, not to evaluate a sequence but to address specific research questions.

In line with our definition of CDIP, we deployed various styles of interaction with student teachers.

In the first part of the interview (up to the end of Step 2), interviewer input was designed mainly to clarify student teachers' LRs. To initiate the dialogue ('Prel' in Tables 2 and 3), student teachers were asked to say what came to mind when they heard the word 'osmosis'.

During interview step 1, the discussion was organized around documents currently found online or in textbooks stating that solute concentration is the same in both compartments at equilibrium. For this purpose, we used drawings like those in Figure 3 for instance (from Wikipedia), along with an explicit text such as the following from Bouissy et al. (1987, p. 110):

(...), a situation of non-equilibrium is going to happen (...) the flow of solvent continuing until a new equilibrium is realized (minimum free energy). Therefore, when the concentrations in $\mathrm{A}$ and $\mathrm{B}$ become equal, there will be different levels in the two compartments $(\ldots)$, and therefore a difference in pressure $\Delta \mathrm{p}=\mathrm{p}_{\mathrm{A}}-\mathrm{p}_{\mathrm{B}},(\ldots)$ (Bouissy et al. 1987, 110)

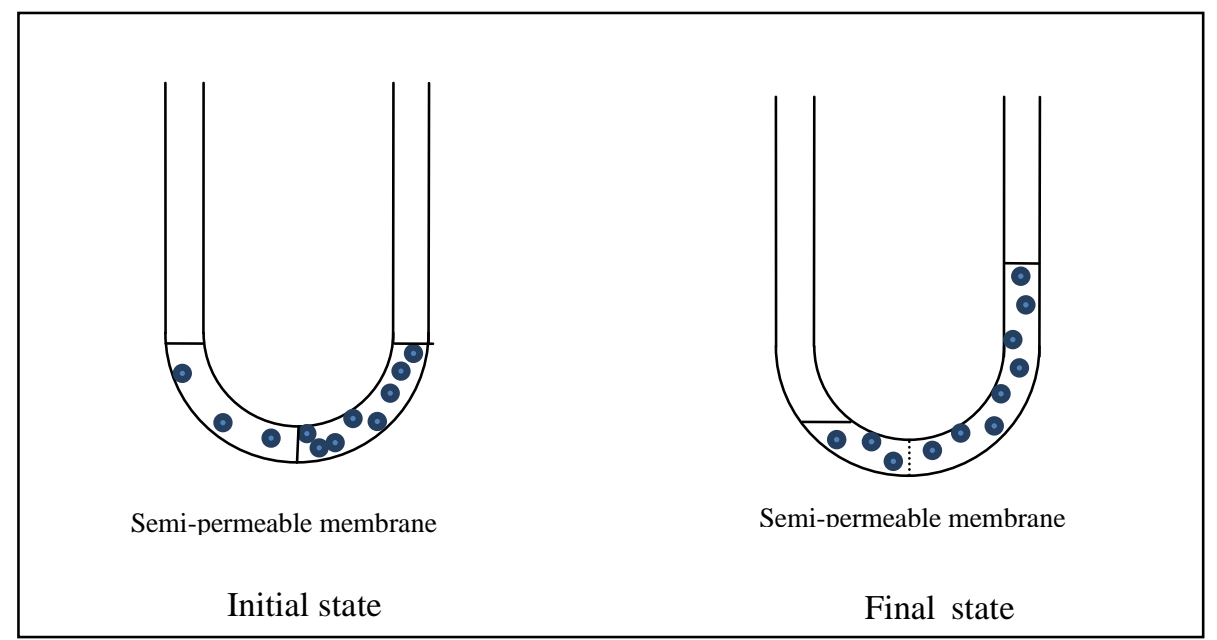

Figure 3. Drawings suggesting the equality of solute concentrations at osmotic equilibrium. 
In the absence of any critique of such documents, the interviewer introduced the idea that a symmetrical situation (i.e. with the same solution and the same levels on both sides) is at equilibrium, and that, according to the texts at hand, this would also be true for the same solution at differing levels. At the end of interview step 1, where still needed, the interviewer introduced the idea that both solute concentration and pressure differ across the membrane at equilibrium, defining osmotic pressure. A passage from the textbook quoted above (Bouissy et al. 1987, p.109) was read, ending with the relationship $\pi=\mathrm{c}_{\mathrm{B}} \mathrm{kT}$ and recalling the meaning of $\mathrm{c}_{\mathrm{B}} \mathrm{kT}$ as the pressure in a perfect gas of volume concentration $\mathrm{c}_{\mathrm{B}}$ and absolute temperature $\mathrm{T}$ in case this was not obvious to the interviewee.

Two points were discussed during interview step 2. First, proceeding from the above text, a discussion was initiated as to whether pressure in a solution or in a mixture of gas is to be seen as the sum of two partial pressures, each related to a single component. Second, à propos the reduced pressure at the top of Mont Blanc, discussion was proposed as to which physical quantities in liquid water change during an isothermal change in pressure. In adapting to students' responses, these two questions were not discussed in the same order with all students.

During the third step [Step3], students are presented with a discussion of osmosis taking into account the full complexity of osmosis between solutions where nonnegligible interactions exist between solute and solvent. The discussion ends up on the $a$ priori frustrating conclusion that chemical potential is then the only reliable tool of analysis because of the complexity of molecular interactions.

The final step focuses on students' appreciation of the interview as a whole. Students are invited to express their views about what they have learned, the value of their interaction with the interviewer and their level of intellectual satisfaction.

Throughout all interviews, the previously analysed lines of reasoning (Table 1) were kept in view.

\section{Processing of interviews}

Given our research question (What links can be identified between the development of conceptual understanding and critical attitude in physics students?), we chose to focus on the introduction [Prel] and interview steps 1 and 2-that is, on the most interactive part of the interview. In contrast, the end of the interview was conducted in a more authoritative style, for which reason we consider it a priori less indicative of interviewees' personal dynamics. For this reason, interview step 3 (which was analyzed for only four students, as the end of the first interview was not usable) will be reported in much less detail here.

This investigation is a case study of a limited sample. To lend more weight to possible convergences among observations and to capture any more idiosyncratic phenomena, we systematically noted the precise number of comments that fitted our categories. Given the small number of interviewees (5), these frequencies clearly offer only a preliminary picture.

\section{Coding of conceptual aspects}

In coding the conceptual content of students' comments, we referred first to the LRs defined above (Table 1). In the quotes with corresponding codes that follow, a minus sign indicates a comment that contradicts the relevant LR. We also highlight 
some comments that seem indicative of a significant step forward $(s f)$ in the student's analysis of the issue in question. Note that ' $s f$ " is relative to what they said previouslythat is, to an idea previously expressed. As in the following excerpts, we mention each time in italics the LR that is reconsidered (e.g. $\omega^{-}$indicates a denial of $\omega$ ) or the new element that is introduced.

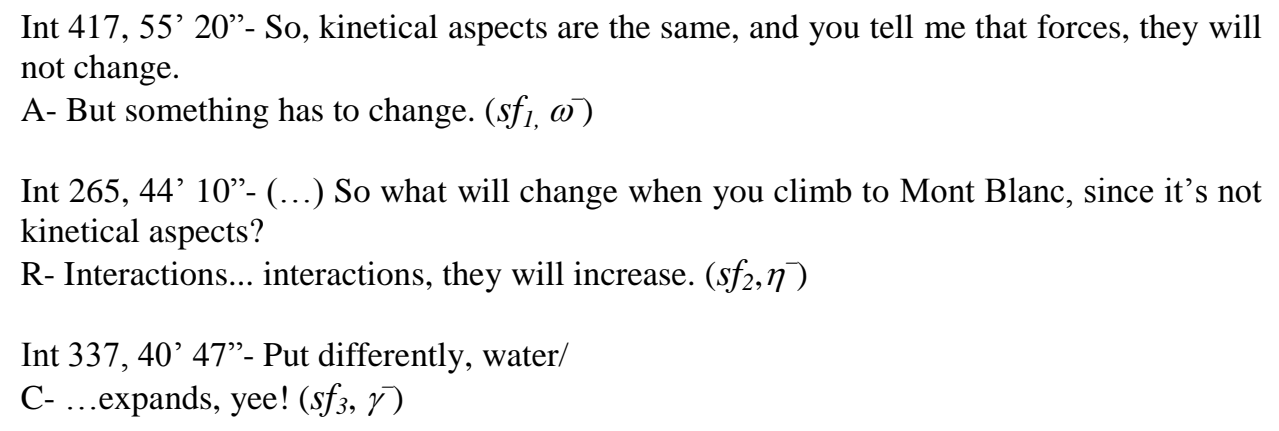

\section{Coding of MCA aspects}

The codes mem+ or mem- refer to instances where students spontaneously say they remember well or not what they have learned about osmosis. Indicators of students' satisfaction $\left(m^{+}\right.$: Yeees!), dissatisfaction ( $m$ : I don't like ckT in water) or surprise (!: I had never thought of that before) were also defined. These also include a silence longer than four seconds (sil), a criticism of one's own previous answer (self: I was wrong.) or an explicit doubt ( $d$ : 'I cannot justify my answer'). Direct critiques are also pinpointed (crit: But this, it's not possible!). As discussed above, we see such comments as indicators of entangled (MCA) components of students' intellectual dynamics. We also use the label meta for metacognitive comments that are explicit and irreducible to the $M C A$ codes as defined. $M C A$ codes will be illustrated in the quotes that follow.

\section{Crucial questions: a double indicator}

We also pinpointed 'crucial questions' $(q)$ that we see as relevant indicators of both conceptual and critical development. Crucial questions are defined here as direct questions or explicitly formulated needs addressing the meaning of what we consider pivotal aspects of the targeted explanation of osmosis. What, for instance, is the meaning of 'osmotic pressure', or 'pressure of water', or 'pressure due to water' (in a solution), or 'hydrostatic pressure'?

Such crucial questions are clearly relevant at a conceptual level; they may even be said to constitute 'steps forward' as defined earlier. More surprisingly, we also count them among $M C A$ indicators, evidencing an active search for meaning beyond mere doubt and destabilization, as in the following excerpts:

\footnotetext{
Int 143, 13' 28'"- I've asked you what is it, osmotic pressure?

T- I can't manage to define it, I thought I had an argument but actually

I can't manage to finish it.

- What prevents you from concluding?

- Err, the notion of pressure in water. $\left(q_{\text {pwat }}\right)$

A 332, 44' 55'- I don't know at all what ' $\mathrm{p}_{\mathrm{wat}}$ ' means (referring to Bouissy et al. 1987, $p$. 109). (q $\left.q_{\text {pwat }}\right)$
}

The coding negotiated between the two authors is illustrated by numerous excerpts. On the basis of this preliminary identification of presumably relevant LRs (Table 1) and 
the coding procedure for $M C A$ aspects, we constructed a tentative mapping of student teachers' intellectual dynamics in the first part of the interview. Beginning from a complete mapping, we extracted two simplified tables: one for conceptual aspects (Table 2) and one for MCA aspects (Table 3). Precise chronology is then abandoned, but the order of coded events is preserved. We hypothesize that crucial questions $(q)$ and steps forward ( $s f$ ) may be important markers of the links between the two components of students' intellectual development considered here. For that reason, these events are included in both tables, enabling the reader to partly synchronize the two. Finally, all the excerpts are timed from the start of the interview, which gives an idea of how long it took for student teachers to reach a given intellectual step.

\section{Main results}

The goal in the first part of the interview was to progress towards two conceptual targets, which we see as preparatory to the explanation provided in Step 3. We comment first on occurrences of LRs (Table 2); then, in light of crucial questions $(q)$, steps forward ( $s f$ ) and $M C A$ indicators (Table 3), we attempt to further characterize student teachers' intellectual dynamics to the end of step 2. Finally, results related to step 3 will be briefly summarized, along with $M C A$ comments collected in the final step.

\section{Prior to step 3: students' LRs}

Table 2 shows the LRs that we identified in the first part of the interview. The main findings concerning these LRs are as follows.

In the introductory part (Prel), the dominant feeling seems to be hesitation and vague reminiscences, with mentions of 'mixture' (student teacher: R), 'chemistry' (M), 'biology' (M), 'diffusion' (C, M) and 'chemical potential' (A, C, M).

The view that the solute will migrate towards the less concentrated solution $\left(\mathrm{LR}_{\varepsilon}\right)$ was expressed by only one student:

R 16,5 ' 07 ''- I would have expected it to pass in the reverse direction $(\varepsilon)$

Teleological lines of reasoning about osmotic pressure or, more generally, a difficulty linked to meanings associated with the term 'pressure' $\left(\operatorname{LR}_{\delta}\right)$, are observed in three students (Step 1: T, R; Step 2: T, M).

Int 73, 7' 21"'- The definition of osmotic pressure, what is it?

T- So, if we take the initial situation, out of equilibrium, it is what causes a global migration from one side to the other. $(\delta)$

M 142, 25' 05', - For me, since the beginning, it's as if there would be two different pressures. (...)

-You tell me this now. Go on, go on, it's interesting.

- Pressure due to a liquid with different heights and a chemical pressure due to a difference in concentration in two media on both sides of a wall. $(\delta)$ 
Table 2. Conceptual aspects of students' intellectual dynamics during the first steps, including crucial questions and steps forward.

\begin{tabular}{|c|c|c|c|c|}
\hline & Prel. & Step 1 (critique of diagrams) & ( $\pi=$ ckT in liquids, & Mont Blanc, $\pi$ in gas) \\
\hline A & $\mu$ & $\begin{array}{lllll}\alpha & \alpha & \varepsilon & \alpha & \alpha \\
\alpha & \tau^{-} & & \end{array}$ & $\chi^{-} \quad \alpha \quad \alpha \underset{q_{p w a t}}{\alpha} q_{\text {psolute }} \chi^{-} \psi^{-}$ & $\chi_{\mathrm{q}_{\mathrm{pwat}}}^{-} \psi^{-} \omega \gamma \eta \eta_{s f_{1}}^{-} \alpha^{-}$ \\
\hline
\end{tabular}

$\begin{array}{lllllllllllll}\mathrm{C} & \operatorname{dif} \\ \mu \tau & \alpha & \alpha & \mu & \tau^{-} & \gamma^{\prime} & \gamma^{-} & \sigma^{-} & \psi^{-} & \tau^{-} & \text {wat }= & \tau \\ & & & & & \mathbf{q}_{\gamma} & s f_{3} & & & & \end{array}$

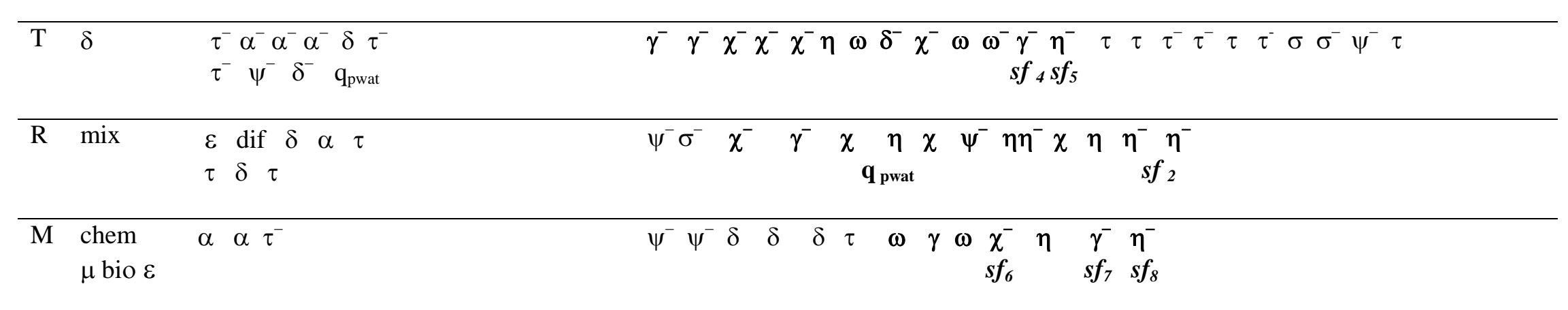

Codes for the LRs are defined in Table 1. Codes for 'crucial questions' and $s f$ are defined in the text. Other codes include: $\mu$, chemical potential; dif, diffusion; mix, mixture; chem, chemistry; bio, biology; wat=, water in the same state across the membrane. A minus sign indicates 'the contrary of'. A given code is repeated only when more than 10 exchange turns intervened in between. Chronological order: in Step 1, left to right and top-down; in Step 2, left to right. In bold: during discussion of water on Mont Blanc. 
Table 3 MCA aspects of students' intellectual dynamics during the first steps, including crucial questions and steps forward.

\begin{tabular}{|c|c|c|}
\hline Prel. & Step1(critique of diagrams) & Step 2 ( $\pi=$ ckT in liquids, Mont Blanc, $\pi$ in gas) \\
\hline A mem $^{-}$ & ! self ${ }_{\alpha}$ self- $d_{\alpha} d_{\tau} d_{\tau}$ & 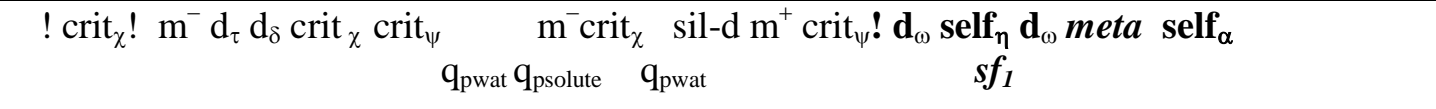 \\
\hline $\mathrm{C} \mathrm{mem}^{-}$ & $\begin{array}{llrlll}\text { mem }^{-} & \text {d } & \text { sil } & \text { sil } & \text { d } & \text { crit }_{\alpha} \\
d_{\tau} & d_{\tau} & \text { self } & & \end{array}$ & 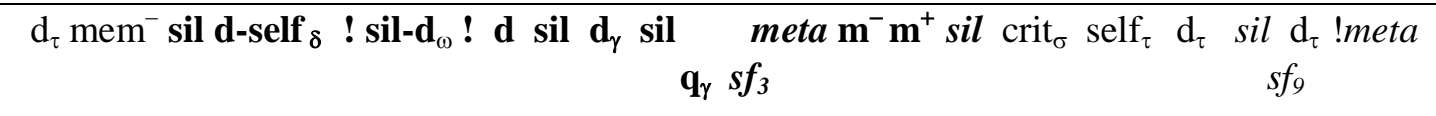 \\
\hline $\mathrm{T} \mathrm{mem}^{+}$ & $\begin{array}{l}\text { mem }^{+} \quad \operatorname{crit}_{\alpha} \quad \operatorname{crit}_{\alpha} \quad \operatorname{crit}_{\alpha} \\
\text { d- } \text { self }_{\delta} \quad \text { d-self } \text { self }_{\delta} \quad \operatorname{self}_{\delta} \quad d_{\chi} \\
\text { q }_{\text {pwat }}\end{array}$ & 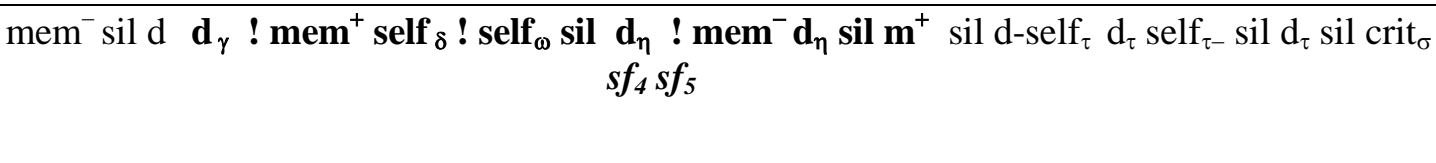 \\
\hline $\mathrm{R}$ mem $^{-}$ & $\begin{array}{lllll}! & !^{-} & \operatorname{self}_{\tau} & \text { sil } & \text { sil-d } \\
{ }_{\alpha} & \text { sil }\end{array}$ & 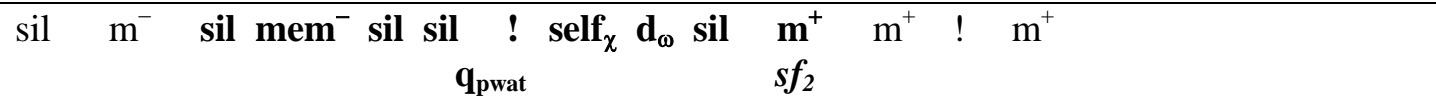 \\
\hline $\mathrm{M}$ & sil $\mathrm{d}^{-}$ & 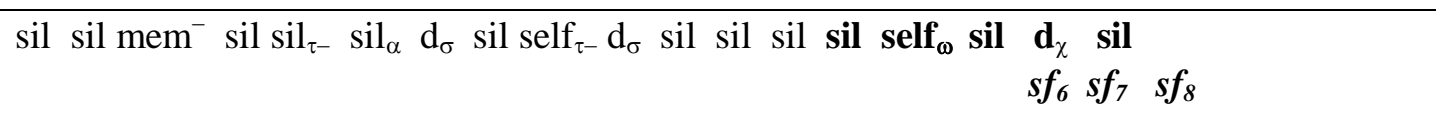 \\
\hline
\end{tabular}

$M C A$ codes are defined in the text; indexes specify the topic to which a 'crucial question', a critique, a self-critique or a doubt relates. A given code is repeated only when more than 10 exchange turns intervened in between. Chronological order: in Step 1, left to right and top-down; in Step 2, left to right. In bold: during discussion of water on Mont Blanc. 
$\mathrm{LR}_{\alpha}$ is widely relied on (A, R, M, C), mainly in Step 1.

R 20, 6' 06"- Here, to get the same concentration, the solute rises up.

-Your idea, it's that we would go towards a situation with the same concentration?

$-M m m m(. .$.$) I've tried to get the same concentration here and here. (\alpha)$

$\mathrm{LR}_{\alpha}$ seems to be very resistant to change. This was also observed further into the interview, after a previous dialogue on this topic.

A 254, 36' 20"- Yes, but if water went that way, after that there would be a difference in concentration.

- Ah yes but...

- I thought there should not be any difference. $(\alpha)$

To a lesser extent, the situation of a "shifted" equilibrium was said to be very disturbing $\left(\mathrm{LR}_{\tau}: \mathrm{R}, \mathrm{C}, \mathrm{A}\right)$ :

Int 31,8 ' 22 " - Here is what you've finally calculated; it makes it possible to calculate a difference in pressure. For example, the difference in pressure near the membrane, what do you think it is?

R- sil I would've put it equal both sides. $(\tau)$

A $12615^{\prime} 05^{\prime}$ - What's strange is to know that there is an equilibrium that can remain shifted. $\left(d_{\tau}\right)$

In brief, contrary to $\mathrm{LR}_{\varepsilon}$, three lines of reasoning mentioned in Table 1 relating to Step $1\left(\mathrm{LR}_{\delta}, \mathrm{LR}_{\alpha}, \mathrm{LR}_{\tau}\right)$ seem to impact significantly on student teachers' approach to osmosis.

Turning now to the molecular determinants of pressure in gas and liquids, and ultimately to osmosis in solutions, it is observed (Step 2) that students are not entirely without previous knowledge. Several students explicitly and spontaneously mentioned the existence of interactions in water $\left(\chi^{-}: \mathrm{A}, \mathrm{T}, \mathrm{R}, \mathrm{M}\right)$, seen as attractive $(\mathrm{T}, \mathrm{R}, \mathrm{M})$, and interactions between solvent and solute ( $\psi^{-}:$all $)$. This explains their reluctance $\left(\sigma^{-}: \mathrm{C}\right.$, $\mathrm{T}, \mathrm{R}$ ) to accept an additive analysis in terms of partial pressures. However, this knowledge proves generally insufficient to analyse the presented situations.

In relation to pure water, several relied on LR $\omega$ ("water is water and does not change': A, T, M); $\mathrm{LR}_{\gamma}$ ('water is incompressible and cannot expand': A, C, M); or $\mathrm{LR}_{\eta}$ ('there are attractions in water but they cannot change': $\left.A, T, R, M\right)$ :

Int 273, 30'13"' - They will attract each other the same?

$\mathrm{T}$ - For me yes.

- OK.

- I dont' see any reason why they would attract each other less. $\left(L R_{\eta}\right)$

As shown by this last comment, it is striking that some students who admit the existence of attractive interactions in water are unable to take these into account when it comes to explaining a change in pressure inside the liquid (A, T, R, M). In this regard, a noteworthy comment suggests that water pressure could change only through kinetic aspects (i.e. in relation to temperature and molecular collisions $-L R_{\chi}$ ): 
R 228, 37' 40"- Actually, when I try to figure out what's up in it, I always come back to kinetical pressure. $(\chi)$

\section{Student teachers' intellectual dynamics before Step 3: crucial questions, steps forward and MCA aspects}

To further analyse student teachers' intellectual dynamics before Step 3, we examined their responses at $M C A$ level, taking the view that 'crucial questions' and 'steps forward' had indicative value in this regard. Interviewees' attitudes seemed to differ before the end of Step 1 and in Step 2.

Concerning the preliminary question and Step 1 (i.e. first contact with the topic and discussion of the misleading drawings), relatively quick destabilization was observed in most student teachers. From the start, three of them (A, C, R) commented on their lack of previous knowledge (as did the other two later). Four interviewees expressed selfcriticism and doubts (A, C, T, R). The student teachers quickly seemed to feel that the topic was complex and that they could offer no adequate explanation for it. As highlighted above, the very meaning of 'osmotic pressure' seemed unclear to them.

In this context, only one student teacher was able to criticize the proposed diagrams, even though it was possible to do so very simply. Relying on previous knowledge, $T$ said at once that these diagrams were wrong. He was also able to find the counterargument that other student teachers were offered later on, starting from a symmetrical situation (i.e. same concentration and levels in both branches of the Utube):

$\mathrm{T} 52,5$ ' 36"- I would have conducted a similar experiment with the same levels (...) (nine exchange turns)

T- So in order to convince people that it's not possible starting from this situation, I would add some height in one of the compartments, saying I have just disrupted the equilibrium, therefore necessarily the system will evolve.

As to the other student teachers, their persisting tolerance of the diagrams seemed to echo their destabilization with regard to the whole field of osmosis. Clearly, it was difficult for them to be critical about $\mathrm{LR}_{\alpha}$, even for $\mathrm{C}$ who remarked that where solute concentration was zero in one compartment, the diagrams suggested that water would pass endlessly from one side (pure solvent) to the other (solution). Only one student teacher (M) did not express any doubt, although his responses were not those of an expert. In his case, direct expressions of doubt were replaced by numerous silences.

To sum up, what was observed until the end of Step 1 was principally destabilization, doubt and critical passivity in respect of LR $\alpha$. Interestingly, only one 'crucial question' was posed in this period (quoted above), and its author was the student who seemed the most self-confident (T).

As for step 2, MCA codings (Table 3) reflect significant critical attitudes among student teachers. Their critiques are for the most part explicitly based on previous knowledge, particularly concerning the existence of molecular interactions in water $(\chi-)$ or between solute and solvent $(\psi, \sigma)$. Probably for that reason, student teachers did not show the same hesitancy as in their previous comments about $\mathrm{LR}_{\alpha}$. Interestingly, in contrast to Step 1, Step 2 is characterized by concentrated occurrences of 'crucial questions' (5/6), indicating an increased concern about the meanings of terms relating to pressure and molecular aspects. Note that such questions were not frequent, nor did they emerge early in the interview. 
The example of reduced pressure in a glass of water brought to the summit of Mont Blanc seems to have had a remarkable impact. A retrospective comment sums up the general feeling about the problem posed by this apparently unchanged water:

T 308, 58' 19'- I never thought of it before, I had not considered this question. (!)

The discussion of this situation prompted many self-critiques (all), and comments expressing surprise (A, C, T, R) or doubt (all). Two explicit metacognitive comments attest to these experiences:

\section{A 446, 1h 00' 30"-(Concerning the fact that something has to change in water when it is brought to an altitude) What else can I do? I don't have the choice. I don't have the choice. (meta) \\ C 302, 37' 20"- Err I don't know. We need something to explain this/ $\mathrm{mmm} /$. We try to explore all avenues! Err, we must explain this stuff. (meta)}

For all of the interviewees, the first $s f$ were taken during this discussion. Interestingly, for 4 out of the 5 student teachers, these $s f$ had also been preceded by crucial questions, bearing on the meaning of quantities relating to pure water $(A, T, R$, C). These $s f$ were soon followed by metacognitive comments or expressions of satisfaction or retrospective frustration:

$\mathrm{T} 362,40$ '52"- (After the link between water expansion and change in attractive forces had been explained) This provides me with what was lacking in my line of reasoning. (meta, $m+$ )

We believe this confirms that these $s f$, coming as they do after (late) crucial questions, are of particular importance in student teachers' intellectual dynamics, at the intersection between conceptual and $M C A$ lines of development. They are significant markers of this (self-)critical moment, during which students truly engaged in a search for comprehension. By the end of Step 2, comprehension of osmosis was still very limited, but a dynamics of reasoning seems to have been activated. All student teachers were observed to make other $s f$ in Step 3, following strong scaffolding.

\section{The end of the interview}

As indicated earlier, we will not report extensively that part of the interview devoted to the interviewer's explanation of osmosis (Step 3), which was presented in a very directive style. Only four interviews $(\mathrm{C}, \mathrm{T}, \mathrm{R}, \mathrm{M})$ covered this second part as required. All students seemed at ease in following the interviewer's input, as no crucial question of meaning was raised during this step. All accepted the arguments presented and more or less quickly made comments explicitly contradicting their previous views $\left[\mathrm{C}\left(\alpha^{-}, \sigma^{-}, \psi^{-}\right), \mathrm{M}\left(\gamma^{-}\right), \mathrm{R}\left(\alpha^{-}, \chi^{-}, \omega^{-} \tau^{-}\right), \mathrm{T}\left(\gamma^{-}, \alpha^{-}, \tau^{-}\right)\right]$; for instance:

\section{R 328, 1h 02' 27'- Now that we have these terms here, I don't expect any more to find it (pressure) equal across the membrane, given that now I've understood this difference in pressure, we have a difference in concentration, sure. $\left(\alpha^{-}\right)$}

The student teachers' final comments confirm their awareness of the limits they encountered in their first attempts to reason about osmosis, prompting retrospective selfcritiques. Interviewees also actively expressed their surprise at discovering new ways of thinking ("Now, I have a new way to think"). Some severe judgments were also expressed concerning the documents discussed at the beginning of the interview. In the same way, student teachers expressed metacognitive judgments on their previous approach of osmosis. 
C 452, 54' 28'"- Anyway, this exercise, once you solved one, it was OK; all the exercises on osmotic pressure were the same, we used to put chemical potentials, (...), we were happy, err, but we never looked into what really happened in osmotic pressure and what's up. (meta)

The situation of reduced atmospheric pressure at Mont Blanc was retrospectively valued:

C 662, 1h 24' 03"- Yes (Mont Blanc and sea level), that's not bad to introduce notions of kinetic and dynamical pressure, euh $\mathrm{mmm},(\ldots)$ after that I find that the transition to salted water is rather easy. $\left(\right.$ meta,$\left.m^{+}\right)$

We also observed some awareness, and some regrets, in relation to the incompleteness of the explanation they had been presented with (which was made quite explicit by the interviewer). However, the students realized that acknowledging the limits of simple explanations was part of the rules of the game in physics, and their comments were balanced:

Int 357, 1h 08' 40"- Aren't you completely frustrated that, finally, I didn't lead you to the ultimate result?

- No, because I understand a phenomenon that I had not understood before, and voilà, it will come later on. $\left(\right.$ meta,$\left.m^{+}\right)$

\section{Recapitulation and discussion}

We examined the progression of five student teachers relating to both conceptual and critical aspects during an interaction with an interviewer that lasted about an hour and a half. The conceptual target was an integrated comprehension of osmosis; by 'integrated' we mean a sense of the links between a macroscopic description of osmosis and a molecular approach. Given our focus on the co-development of conceptual and critical aspects, integration also targeted these two components of interviewees' intellectual activity.

As explained in introduction, the main goal of this investigation was to examine the possible links between conceptual and critical development in our interviewees. In so doing, we had to define, then observe, what we consider to be a conceptual progress concerning osmosis. We recapitulate hereafter this part of our study before discussing what concerns our main research question.

Concerning osmosis, we surmised that three main conceptual knots block interviewees' path in comprehending this topic. Each of these knots corresponds directly to an interview step as described. First, it was important for student teachers to understand that what is equal on both sides of a semipermeable membrane at osmotic equilibrium is a physical characteristic of the solvent-in particular it is not solute concentration. A second conceptual knot identified as consistently important was to understand the mechanisms of adaptation of water (seen here as a prototype of a solvent) to an imposed isothermal change in pressure, entailing an awareness of the existence and centrality of molecular interactions. We viewed this as an opportunity to clarify meanings associated with the term 'pressure', introducing corresponding relevant quantities for the state of the solvent. The final conceptual knot was to understand the role of solute concentration in influencing the state of the solvent at a given temperature. This paper has focused on the first part of the interview-that is, the brief introduction and the two first conceptual knots just mentioned. We argue that these 
conceptual targets are prerequisites for meaningful appropriation of an explanation of osmosis, and our interest lies in this preparation for explanation of the phenomenon itself.

The results confirm that these conceptual knots are indeed pivotal. In this regard, several lines of reasoning constituting potential obstacles were observed. For instance, most of the students willingly accepted or actively claimed that solute concentrations should be equal at equilibrium; this confirms the earlier finding of Odom and Barrow (1995) and Shen et al. (2014). As the initial cause of the phenomena was (in most cases) a difference of concentration, equilibrium was seen as linked to the disappearance of the cause, with no retroaction of the effect (increased pressure on one side). Note that the finalist style of phrases used to describe the migration of solvent (e.g. 'tending to equalize solute concentrations') is likely to reinforce this approach.

More informative are interviewees' first responses concerning water's adaptation to a change in pressure. The lines of reasoning that constitute obstacles in this regard are at various 'conceptual distances', so to speak, from the targeted comprehension-an issue which, to our knowledge, has not previously been documented. Not all students see the volume of liquid water as invariable. But although they knew that there were some interactions in water, none of the interviewees was able (unassisted) to link these elements of knowledge to a change in pressure in the liquid. Confronted with the example of a glass of water at a higher altitude, they were at once destabilized and eager to solve the paradox. This remarkable impact is linked, we suggest, to the opportunity this represented to better understand the meaning of the phrase 'pressure of liquid water'. In the second part of the interview, the students seemed to share the interviewer's understanding of terms used. By the end, they had all explicitly invalidated the lines of reasoning that had previously blocked them.

Turning now to our main research question - that is, to the co-evolution of student teachers' conceptual understanding and critical attitude - this investigation delivers data that confirm or complete the findings of the three previous studies. A first phenomenon of note here was the long-delayed critique of documents that suggested the equality of solute concentrations at osmotic equilibrium. Despite simple counter-arguments offered by the interviewer or even identified by the student teachers themselves, this effect was observed in 4 out of 5 interviewees. Previous results (Mathé \& Author 1 2009, Author 2 \& Author 1 2015, Author 1 \& Author 2 2016) suggest that many interviewees felt it necessary to reach a threshold of comprehension-student-dependent but often higher than mere logical necessity-before daring to critique an incomplete or incoherent explanation. This tendency was again observed here.

In fact, this phenomenon impacted on the whole discussion beyond analysis of the first documents. One overall conclusion of this investigation is the crucial role of the meanings ascribed to terms describing pressure in liquids. Student teachers were slow to realize how their understanding of the osmotic process was limited by imprecise comprehension of the concept of pressure; self-critique in this regard was rarely observed in Step 1.

It proved difficult to capture precisely the decisive elements in interviewees' evolution from blurred or finalist expressions to more precise use of the term 'pressure' and associated adjectives, and we chose to take their 'crucial questions' as privileged indicators in this regard. Interestingly, these crucial questions seemed more or less distant precursors of the conceptual 'steps forward' referred to above. These small intellectual events - crucial questions and subsequent steps forward-represent nodes in the entanglement of conceptual and metacognitive-critical-affective lines of development. In previous investigations (Author2 and Author 1 2015, Author 1 and 
Author 2 2016), precise localization in time of such events was not always possible, given student teachers multiple to and fro, the silent progress of their reflections and their delayed expression. Here, the particular example of water at reduced pressure seemed to prompt rapid intellectual evolution, both conceptual and critical.

In summary, as in our previous studies, these student teachers' intellectual dynamics seemed to develop along two entangled lines. Conceptually, they first exhibited several lines of reasoning that were incompatible with accepted physics; then, after a delay, and particularly in relation to the Mont Blanc example, some crucial questions emerged about terms describing pressure in liquids. These questions paved the way for visible steps forward until, finally, previous inappropriate lines of reasoning were rejected. In relation to $M C A$ aspects, students seemed to pass from a wish to remember to a wish to understand, in a kind of 'critical crisis' underpinned by selfcritique. While critique of inappropriate schemas or statements was at first absent or at best hesitant, crucial questions and steps forward eventually emerged, and the contested documents were explicitly critiqued, accompanied by active and willing expression of metacognitive comments.

In this regard, the present investigation aligns with previous studies already quoted (Mathé \& Author 1 2009, Author 2 \& Author 1 2015, Author 1 \& Author 2 2016) supporting a first categorization of the intellectual dynamics of conceptual and critical co-development. We identify 'delayed critique' as the desire to understand a phenomenon more fully and beyond logical necessity before rejecting an incomplete or incoherent explanation of it (Fig. 4). In contrast, an 'early critique' consists in accepting the conclusions of a relevant counterargument, even with an as yet incomplete comprehension of the topic. In one of the studies just quoted (about radiocarbon dating: Author 2 \& Author 12015 ), there is evidence of 'expert anesthesia of judgment' when a person knows a topic very well and accepts an incomplete or inconsistent explanation without expressing any critique (see also Author 1 2009). Table 4 recapitulates the numbers of interviewees manifesting each of these intellectual dynamics for each topic addressed. 


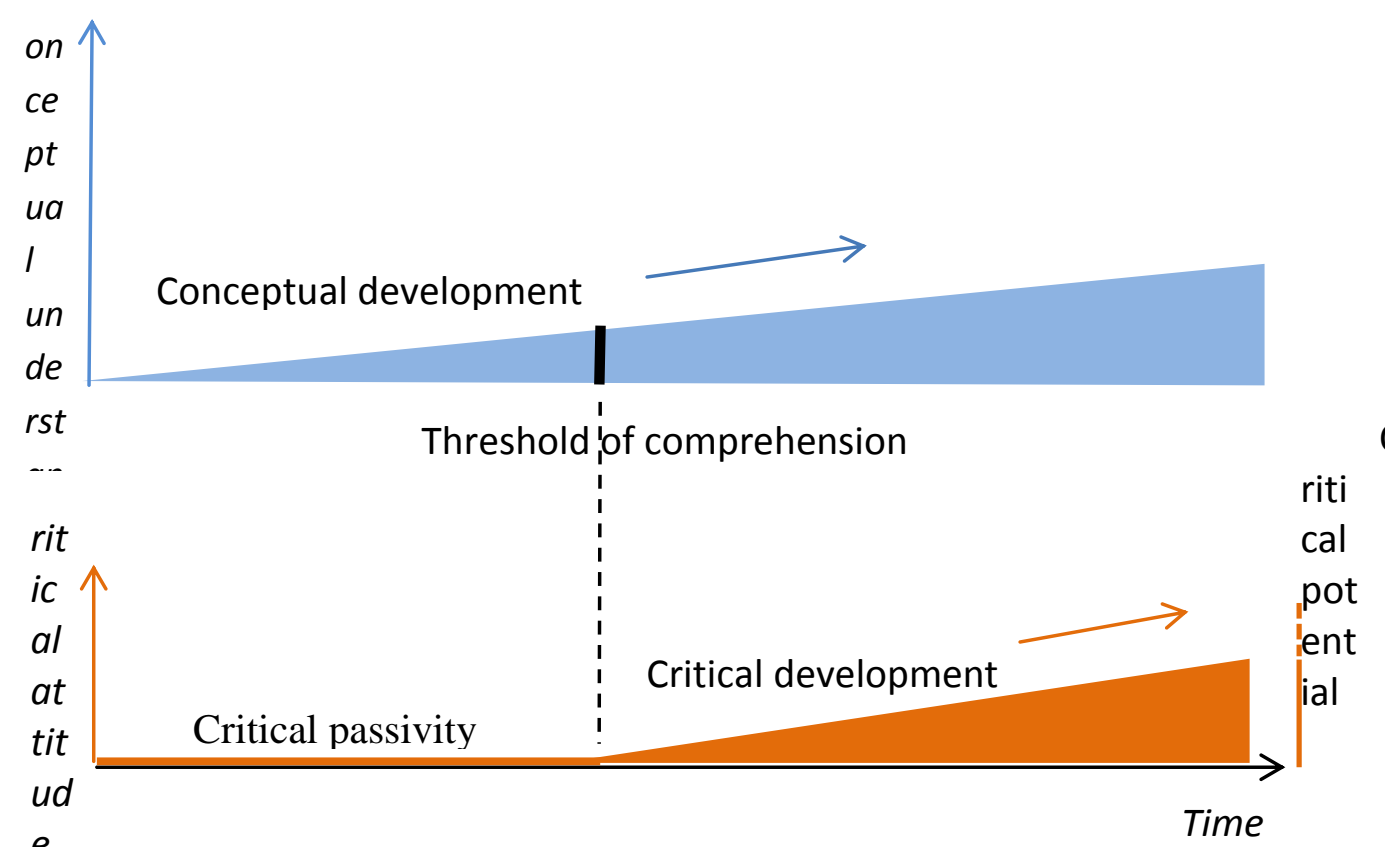

Figure 4. Codevelopment of conceptual understanding and critical attitude: a tentative model for the case of "delayed critique" (adaptation of this diagram for the cases of "early critique" and "expert anaesthesia" is shown in Table 4).

Table 4. Numbers of interviewees manifesting each of the three identified intellectual dynamics in three previous investigations, plus the present one.

\begin{tabular}{|c|c|c|c|c|}
\hline $\begin{array}{l}\text { Topic } \\
\text { Authors }\end{array}$ & Sample & $\begin{array}{l}\text { Delayed } \\
\text { critique }\end{array}$ & Early critique & $\begin{array}{c}\text { Expert } \\
\text { anaesthesia* }\end{array}$ \\
\hline $\begin{array}{l}\text { "Isobaric" hot air } \\
\text { balloon } \\
\text { Mathé \& Author } 12009\end{array}$ & $\begin{array}{c}14 \\
\text { future science } \\
\text { journalists }\end{array}$ & 14 & 0 & 0 \\
\hline $\begin{array}{l}\text { Radiocarbon dating: } \\
\text { Constancy of }{ }^{14} \mathrm{C} /{ }^{12} \mathrm{C} \\
\text { ratio in the } \\
\text { atmosphere } \\
\text { Author } 2 \text { \& Author } 12015\end{array}$ & $\begin{array}{c}10 \\
\text { student teachers } \\
\text { (physics) }\end{array}$ & 8 & 0 & 2 \\
\hline $\begin{array}{l}\text { The survival blanket: } \\
\text { "Put the silver side } \\
\text { inside to protect } \\
\text { against cold" } \\
\text { Author } 1 \text { \& Author } 22016\end{array}$ & $\begin{array}{c}7 \\
\text { student teachers } \\
\text { (physics) }\end{array}$ & 6 & 1 & 0 \\
\hline $\begin{array}{l}\text { Osmosis: } \\
\text { "Same solute } \\
\text { concentration in each } \\
\text { branch of the U-tube } \\
\text { at osmotic } \\
\text { equilibrium" } \\
\text { (This article) }\end{array}$ & $\begin{array}{c}5 \\
\text { student teachers } \\
\text { (physics) }\end{array}$ & 4 & 1 & 0 \\
\hline
\end{tabular}

\footnotetext{
* Numerous cases of expert anaesthesia (61/61 physics teachers) were also observed in a study concerning an "isobaric" hot air balloon (Author 1 2009) using written questionnaires
} 
During this study, interviewees' intellectual pathways in their interaction with an expert reflect the intellectual dynamic of "delayed critique" most frequently observed in previous studies. Here again, as in the case of the survival blanket (Author $1 \&$ Author 2 2016), we observed a unique case of "early critique" in discussing osmosis. As in that earlier case (unlike the study involving radiocarbon dating), "expert anaesthesia" did not arise, as none of the interviewees could be considered as an expert on osmosis.

More specific to the present investigation is the precise localization of events likely to trigger rapid conceptual and critical evolution, linked to the issue of reduced pressure at a higher altitude. In this regard, questions about the meanings of terms used to designate a given concept seem to play a decisive role. As emphasised above, beyond the idea of a "threshold of comprehension", it is not always possible to precisely determine the decisive factor in changing interviewees' critical attitude. In so doing, this study illuminates more precisely how a phenomenon observed for research purposes can inform the design of teaching environments.

\section{Final remarks}

This analysis provides strong support for the thesis of a direct interplay between conceptual and critical aspects of student teachers' development; in our limited but converging investigations, these two lines of progression appear intertwined. This suggests that it may be inappropriate to characterize a student teacher as 'having' (or 'not having') a 'critical faculty' (in the current meaning of this term), an idea already challenged by, e.g., Willingham (2008). Here, activation of interviewees' critical potential according to their level of intellectual frustration and/or self-confidence was found to be linked to their comprehension of the topic.

Turning to the implications for physics teaching, the present study suggests that being able to solve classical exercises based on chemical potential or to correctly answer questions about the phenomenology of osmosis does not amount to an integrated comprehension of osmosis. In particular, heuristics like the solvent's 'tendency to equalize solute concentrations' may be efficient in correctly predicting the initial phase of the phenomenon, but they skew understanding of the state of equilibrium, and their finalist style is likely to have epistemological consequences.

Our investigation has identified a number of tools that can be adapted to different teaching contexts to assess both lines of reasoning and readiness to activate critical potential. These diagnostic tools include the identified lines of reasoning, the interview protocol (and in particular the example of water under reduced pressure) and the method for mapping interviewees' intellectual dynamics. These tools can help to enhance teachers' awareness of student needs and so inform the design of learning environments that explicitly target those needs.

The main finding of the present study - in line with our previous investigations - is that, to release critical potential, a threshold of comprehension must be reached that is student-dependent and often higher than mere logical necessity. Granted the limitations of this study, the analysis strongly suggests that to disregard the objective of conceptual structuring would be counterproductive for the development of students' critical attitude. More precisely, these findings illuminate how student teachers manage their 
intellectual resources when interacting with an expert. The identification of varying conceptual and critical co-development profiles may facilitate decisions about teaching goals and strategies, as well as about teacher formation. For instance, the intellectual dynamics of a student teacher who recognizes the relevance of a critique of misleading diagrams but fails to draw any firm conclusion is worthy of further attention. Such cases of "delayed critique" designate a target - to express one's frustration even in the absence of complete comprehension.

It seems likely that intellectual dynamics such as these have important implications for how the individual appropriates teaching documents or popularized resources.

More generally, we suggest that much more can be learned from students' responses to an educational setting if analysis of their comments is not confined exclusively to conceptual aspects - more precisely, more attention should be paid to the possible interconnections between conceptual and metacognitive-critical-affective awareness. We further suggest that investigations of correlations between competences or of cognitive aspects alone will not suffice. For instance in the case of 'expert anesthesia of judgement', weak detection of incomplete explanations may reflect the fact that a person unconsciously completes what is unsaid in the particular text. In other cases, as in the present investigation, a lack of comprehension prevents students from expressing their critical potential. Given this complexity, echoing the position of Hammer and Sikorski (2015), interpreting the findings of correlation-based studies may be hazardous. It therefore seems important to better understand how students can be helped to manage their existing intellectual resources while remaining cautious about their possible limitations. The way a given potential of critique is activated or not may strongly depend on students' evolving comprehension of a topic in conjunction with some psychological aspects. This invites further research on students' intellectual dynamics during interaction with a teacher or with other students. To this end, we propose fine-grained analysis of both conceptual and metacognitive-critical-affective processes in the construction of critical comments.

\section{References}

AlHarbi N. N. S., Treagust D. F., Chandrasegaran A.L. \& Won M. (2015) Influence of Particle Theory Conceptions on Pre-service Science Teachers' Understanding of Osmosis and Diffusion, Journal of Biological Education, 49:3, 232-245.

Author $1 \&$ de Hosson, C. (2015). From a Subtractive to Multiplicative Approach, A Concept-driven Interactive Pathway on the Selective Absorption of Light, International Journal of Science Education, $37: 1,1-30$. 408.

Author 1 (2006). Teaching rituals and students' intellectual satisfaction, Physics Education, 41, 400-

Author 2 \& Author 1 (2015). Co-development of conceptual understanding and critical attitude: analysing texts on radiocarbon dating, International Journal of Science Education, 37, 2038-2063.

Author 1 \& Author 2 (2016). Co-development of conceptual understanding and critical attitude: toward a systemic analysis of the survival blanket, European Journal of Physics, 37 doi:10.1088/01430807/37/1/015702

Bandura, A. (2001). Social cognitive theory: An agentic perspective. Annual review of psychology, 52(1), 1-26.

Besson U. \& Author 1 (2004). Using models at mesoscopic scale in teaching physics: two experimental interventions on solid friction and fluid statics, International Journal of Science Education, 26 (9), 1083-1110. Bélin..

Bouissy, A., Davier, M. \& Gaty, B. (1987). Physique pour les sciences de la vie, tome 2, Paris :

Cabane, B. \& Hénon, S. (2003). Liquides Solutions, dispersions, émulsions, gels, Paris : Bélin..

Diu, B., Roulet, B., Lederer, D. \& Guthmann, C. (1989). Physique statistique, Paris : Hermann. 
Duit, R. \& David, R, Treagust, D.R. (2003). Conceptual change: a powerful framework for improving science teaching and learning, International Journal of Science Education, 25 :6, 671-688.

Ennis, R. H. (1992). The degree to which critical thinking is subject specific: Clarification and needed research. The generalizability of critical thinking, 1992, p. 21-37.

European Commission (2015). Science Education for Responsible Citizenship Report EUR 26893 EN, Brussels

Habermas, J. (1981). The theory of communicative action. Boston: Beacon Press.

Hammer, D. \& Sikorski, T.R. (2015). Implications of Complexity for Research on Learning Progressions, Science Education 99, 3, 424-431.

Jimenez- Aleixandre, M. P., \& Puig, B. (2012). Argumentation, evidence evaluation and critical thinking. In B.J. Fraser, K. Tobin, \& C. McRobbie (Eds.), Second international handbook of science education (pp. 1001-1015). Dordrecht: Springer.

Komorek M \& Duit R (2004). The teaching experiment as a powerful method to develop and evaluate teaching and learning sequences in the domain of non-linear systems, International Journal of Science Education 26(5), 619-633.

Kramer, E. M., \& Myers, D. R. (2012). Five popular misconceptions about osmosis. American Journal of Physics, 84, 694-699.

Linn, M. C., Lee, H.-S., Tinker, R., Husic, F., \& Chiu, J. L. (2006). Teaching and assessing knowledge integration in science. Science, 313, 1049-1050.

Mathé S \& Author 1 (2009). Stressing the coherence of physics: Students journalists' and science mediators' reactions Problems of education in the 21st century 11(11) 104-128

McPeck, J. (1981). Critical thinking and education. New York: St Martin's Press

Odom, A.L. \& Barrow, L.H. (1995). Development and Application of a Two-Tier Diagnostic Test Measuring College Biology Students' Understanding of Diffusion and Osmosis after a Course of Instruction, Journal of Research in Science Teaching, 45-61.

Ogborn, J. (1997). Constructivist metaphors of learning science. Science \& Education, 6, 121-133.

Shen J., Liu O.L. \& Sung S. (2014). Designing Interdisciplinary Assessments in Sciences for College Students: An example on osmosis, International Journal of Science Education, 36:11, 1773-1793, DOI: 10.1080/09500693.2013.879224

Vermunt J D (1996). Metacognitive, cognitive and affective aspects of learning styles and strategies: A phenomenographic analysis. Higher Education 31 25-50.

Wang C.-Y. (2015) Scaffolding Middle School Students' Construction of Scientific Explanations Comparing a cognitive versus a metacognitive evaluation approach, International Journal of Science Education, 37:2, 237-271.

Willingham, D.T. (2008). Critical Thinking: Why Is It So Hard to Teach? Arts Education Policy Review, 109:4, 21-32. 
